\title{
Potential for Distributed and Central Electrolysis to Provide Grid Support Services
}

\author{
Project: Renewable Electrolysis Integrated System Development and Testing \\ NREL Team: Kevin Harrison, Marc Mann, Danny Terlip, and Mike Peters
}

Accomplishment: NREL operated both commercially available low-temperature electrolyzer technologies (PEM and alkaline) to evaluate their response to commands to increase and decrease stack power that shorten frequency disturbances on an alternating current (AC) mini-grid (Figure 1). Results show that both the PEM and alkaline electrolyzers are capable of adding or removing stack power to provide sub-second response that reduced the duration of frequency disturbances.

Context: Management of distributed power systems is expected to become more commonplace as grids and devices become "smarter" and distributed renewable resources become a larger proportion of our energy supply. A critical element for the advancement of smart-grid technologies is managing distributed resources, which includes renewable electricity generation, distributed energy storage, and taking advantage of active (or controllable) loads to provide grid support services like frequency and voltage regulation.

Large-scale hydrogen production using renewable electricity is well positioned to produce near-zero-greenhouse-gas-emission vehicle fuel in the coming years as hydrogen-powered electric vehicles are introduced into the marketplace. An integrated system with advanced sensing and communications will enable grid operators to take advantage of the controllable nature of distributed and central water electrolysis systems to maintain grid stability.

In NREL's configuration (Figure 1), diesel (synchronous) generators are used to power the PEM and alkaline electrolyzers in independent tests. The load simulators are connected to the AC mini-grid to generate frequency disturbances akin to the disturbances caused by severe ramping of wind- and solar-generated electricity sources.

High resolution sensing of the AC mini-grid frequency (nominally $60 \mathrm{~Hz}$ ) generates a control signal for the electrolyzer when the frequency exceeds \pm 0.2 $\mathrm{Hz}$. For example, the load simulator is used to generate a disturbance on the grid (Figure 2, blue), which causes the frequency to drop below the lower limit of $59.8 \mathrm{~Hz}$. In separate tests, a control signal is generated when the frequency reaches the set point, and that signal is transmitted to the electrolyzers to reduce stack power (Figure 2, red and green).
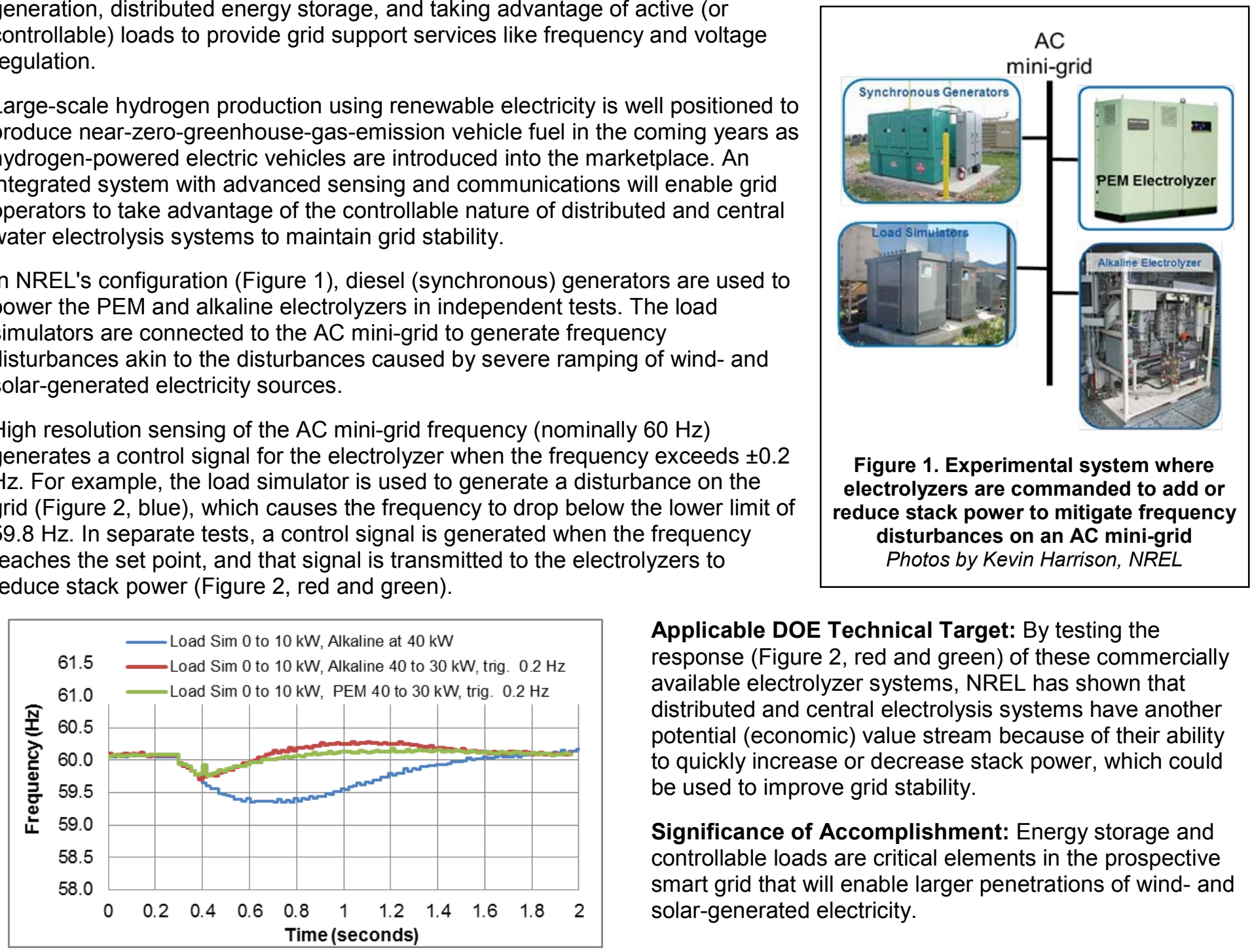

Applicable DOE Technical Target: By testing the response (Figure 2, red and green) of these commercially available electrolyzer systems, NREL has shown that distributed and central electrolysis systems have another potential (economic) value stream because of their ability to quickly increase or decrease stack power, which could be used to improve grid stability.

Significance of Accomplishment: Energy storage and controllable loads are critical elements in the prospective smart grid that will enable larger penetrations of wind- and solar-generated electricity.

Figure 2. Resulting shortened frequency disturbances due to electrolyzers (red, green) with un-mitigated response (blue) 